\title{
Is it worth to continue to analyse the factors of cardiovascular risk among the sailors? Review of literature
}

\author{
Joanna Szafran-Dobrowolska, Marcin Renke, Maria Jeżewska
}

Department of Occupational, Metabolic and Internal Diseases, Medical University of Gdansk, Poland

\begin{abstract}
Background: Cardiovascular diseases are still the most common cause of death from natural causes among seafarers. The aim of the study was to determine which of the cardiovascular risk factors listed in the current recommendations of the European Society of Cardiology occur among seafarers.

Materials and methods: The paper is a review of literature from PubMed Database.

Results: Based on conducted analysis of over 31 papers high prevalence of classic and other cardiovascular risk factors among seafarers was proven. The most common risk factors among off-shore workers are overweight and obesity (over 64\%); moreover, these factors occur more often among seafarers than in the general population. Also hypertension, smoking, type 2 diabetes and unfavourable lipid profile were present more often in this occupational group. In the analysed studies attention was also paid to factors often overlooked in risk assessment such as mental and inflammatory illnesses, unfavourable working conditions and psychological burden. Conclusions: Seafarers have a higher cardiovascular risk because, among other things, the prevalence of "old and new" risk factors among them is higher than in general population.
\end{abstract}

(Int Marit Health 2019; 70, 1: 17-21)

Key words: cardiovascular risk, seafarers, ischaemic heart disease, hypertension, stroke

\section{INTRODUCTION}

According to the current World Health Organisation (WHO) definition, cardiovascular diseases (CVD) are a diverse group of diseases, affecting the heart, as well as large and small vessels, also including, among others, hypertension, ischaemic heart disease and stroke. According to current data, those are the leading causes of death in the general European population [1], as well as the leading natural causes of deaths of seafarers [2]. In addition, according to results of the NAT-POL Plus study [3], which concerned the Polish population and whose authors assessed the prevalence of such risk factors as hypertension, hypercholesterolaemia or diabetes - only about $11 \%$ of Poles aged 19-94 are free from risk factors for CVD. Analyses carried out earlier [4] indicate that cardiovascular risk factors are also common in the seafarer population, with mortality rates in the case of cardiovascular events at sea being much higher than on the land $[5,6]$. It is also worth mentioning that episodes of chest pain were the reason for about 7\% of Telemedical Maritime Assistance Service (TMAS) calls received by the TMAS physician at our centre in Gdynia from 2012 to 2017, and CVD concerned $12 \%$ of all the calls. Approximately $1 / 3$ of the evacuations recommended by TMAS doctors on duty concerned cases of CVD (own).

\section{MATERIALS AND METHODS}

This study analyses articles concerning individual cardiovascular risk factors available in the PubMed, Via Medica - International Maritime Health and Oxford Academic databases. Searching for articles for analysis was done by searching for keywords, followed by searching for key authors. The keywords were selected based on the current Guidelines of the European Society of Cardiology (ESC) [7] on the prevention of CVD and previous publications on documented risk factors [3]; authors were selected based on 
previously analysed work. The search took into account key words in English, Polish and sometimes German languages.

\section{RESULTS}

\section{CLASSIC RISK FACTORS}

The best known risk factors for CVD, also in seafarers, include smoking, hypertension, diabetes and high total cholesterol. Analysis of Pougnet et al. [4] of previous studies from 1990 and 2000 indicates that smoking of tobacco, hypertension (for which average blood pressure $>140 / 90$ $\mathrm{mmHg}$ was considered significant) and overweight (body mass index [BMI] $>25 \mathrm{~kg} / \mathrm{m}^{2}$ ) as well as high cholesterol and glycaemic disorders were common among seafarers. Between 1990 and 2000, the number of seafarers smoking tobacco decreased; however, frequency of other risk factors increased - especially the overweight/obese group of seafarers increased from $47 \%$ to $64 \%$ [4]. A later study done by Oldenburg et al. [8] in 2010, carried out on a group of $46 \mathrm{Ge}-$ rman seafarers confirmed the increased frequency of type 2 diabetes ( $8.7 \%$ vs. $2.9 \%$ ) and smoking ( $39.1 \%$ vs. $33.8 \%$ ), as well as slightly higher mean arterial pressure (132.6 vs. 131.6) relative to general population. The German study [8] also concluded that obesity, type 2 diabetes, arterial hypertension, and smoking were significantly more common in a group of seafarers working more than 15 years on the sea. Also, higher levels of low density lipoprotein cholesterol and triglycerides were found in this group, than in the groups working less than 15 years.

A higher percentage of overweight and obese people than in the general population was also found among seafarers working on Italian ships (Italians, Filipinos and Indians). A study by Natari et al. [9] conducted on a group of about 1150 seafarers was published in 2019. A higher percentage of people with $\mathrm{BMI}>25 \mathrm{~kg} / \mathrm{m}^{2}$ was found particularly for Filipino and Indian seafarers (compared to average BMI values for a given population). Interestingly, in the Italian study, the number of people with hypertension and glycaemic disorders was the same as in the general population.

When talking about obesity, one should also mention the right diet - a diet lowering CVD risk is a diet low in saturated fat, with a high content of fish and fibre and with reduced sodium content [7].

Among Filipino seafarers more than $40 \%$ of respondents consumed a diet rich in fats, and another $27 \%$ diet with a high salt content, which means that about $70 \%$ made dietary mistakes [9]. What's more, almost $80 \%$ of seafarers admitted to consuming alcohol in the last month [10].

In addition, the so-called classic risk factors of CVD include also low physical activity, age, gender and psychosocial factors such as stress [11]. According to Wójcik-Stasiak [5], due to the specific working conditions at sea, discouraging physical exercise during free time (lack of space or adequate equipment for physical exercise), there is often a low level of physical exercise in leisure time among seafarers; as well as the unfavourable ratio of effort level in free time to the level of work-related effort [5]. Both of these factors are considered to be associated with higher overall mortality, especially among people with low levels of fitness [12]. The low activity of seafarers during their stay at sea was confirmed by the Norwegian study [13] in which only $39 \%$ of 577 seafarers surveyed performed physical exercises at least twice a week.

According to the European Maritime Safety Agency (EMSA) report published in July 2018, 98\% of people working at sea are male [14], which is an independent, unmodifiable risk factor for CVD $[7,11]$. In addition, the average age of people with a valid certificate of competency was 43 , which may also be associated with an increased cardiovascular risk [7]. Furthermore, according to a study by Oldenburg and others, the incidence of CVD risk factors among seafarers increases with seniority [8].

Seafarers are also heavily exposed to stress during work resulting primarily from isolation from the family, fatigue, Ioneliness, sleep disorders and communication problems among the multicultural crew on the ship [15].

\section{PREVIOUS CARDIOVASCULAR EVENTS}

According to the ESC Guidelines regarding CVD prevention [7], people with a history of acute myocardial infarction, acute coronary syndrome, stroke or transient ischaemic attack have a very high risk of an acute cardiovascular event. Until 2015, a Regulation of the Minister of Health was in force in Poland, according to which seafarers diagnosed with ischaemic heart disease were considered unfit to work at sea (with the exception of those working at sea for more than 10 years under certain conditions) [16].

This probably led in some cases to suppressing ischaemic heart disease by seafarers of Polish nationality while obtaining a health certificate and thus underestimating the number of seafarers with a positive cardiovascular history [5]. In accordance with the currently valid regulations and regulations in force in Poland [17] and the International Maritime Labour Convention 2006 [18], a seafarer after a so-called cardiac event may be re-admitted after 3 months after certain conditions have been met.

For the cardiac event, the legislator recognises, apart from a myocardial infarction, an electrocardiogram record indicating the post-infarction condition, a newly diagnosed left ventricular block of the atrioventricular bundle, angina pectoris, cardiac arrest; as well as coronary artery bypass grafting and coronary angioplasty [17]. Considering the above and the fact that seafarers holding a certificate of qualifications issued in Poland constitute the second largest 
group among seafarers of European descent [14], one can expect a greater number of patients after a cardiac event among those working at sea.

\section{FAMILY HISTORY}

Also, a positive family history of CVD increases the average cardiovascular risk. According to the ESC guidelines [7], a positive family history is considered to be a case of heart or vascular disease (myocardial infarction, atherosclerosis, hypertension, stroke) in first degree relatives before the age of 55 years in the case of men or before the age of 65 years for women. According to a study conducted in 2010 in Hamburg by Oldenburg et al. [8] on a group of about 160 seafarers sailing under the German flag (104 seafarers were of European descent, 57 came from outside Europe) positive family history concerned about $15 \%$ of seafarers. This is a result similar to those obtained in working men of the same age from the general German population (PROCAM study) $[8,19]$.

\section{CHRONIC DISEASES}

When assessing the general risk of CVD, one can also not forget about chronic diseases other than those classically associated with CVD risk that may affect seafarers' populations. According to the meta-analysis of 24 studies conducted in 2008 by Aviña-Zubiet et al. [20], over 111,000 patients with rheumatic diseases and more than 22,000 acute coronary events, rheumatoid arthritis patients were $50 \%$ more likely to die from CVD compared to the general population. The increased risk concerned both the incidence of ischaemic heart disease and cerebrovascular accidents. What is more, the increase in CVD risk also applies to other rheumatic diseases: gout, lupus and other connective tissue systemic diseases [21]. In this group of patients, risk factors such as obesity/overweight, hypertension and smoking are common, and moreover, patients in this group are also exposed to cardiotoxicity of the used drugs or chronic increase of markers of inflammation [21, 22]. Until 2015, rheumatoid arthritis was a contraindication for work at sea; currently, according to the applicable regulation, a person suffering from connective tissue diseases may be allowed to work at sea after the acute symptoms of the disease have stabilised [17].

European Society of Cardiology also draws attention to the role of mental illness [7], stressing that schizophrenia, depression and post-traumatic stress disorder increase the risk of CVD. In the analysis of 12 studies involving the number of deaths from natural causes among seafarers in 1992-2007 conducted by Iversen [23], it was found that approximately $13 \%$ of deaths were caused by suicide. This number would probably be higher if the number of unexplained disappearances at sea was taken into account, as according to some researchers about half of these cases can be explained by suicide [23]. On the other hand, some researchers believe that the problem of depression and burnout among seafarers is not currently more severe than among workers on land [24]. However, given the prevalence of depression and mental illness; and changes in the legislation that allow personnel with mental issues to work at sea [17], mental disorders can be an important and underestimated aspect in estimating the overall risk of CVD.

\section{LABORATORY TESTS}

Currently, the ESC does not recommend the use of biomarkers in the assessment of cardiovascular risk in the general population [7], indicating a tendency to overestimate the role of biomarkers in CVD risk assessment. The lack of a clear relationship between the concentration of parameters such as $\mathrm{C}$-reactive protein and thyrotropin and higher cardiovascular risk was also found in a Spanish study conducted by Maria del Carmen Romero-Paredes et al. [25] on a group of 334 seafarers during pre-embarkation medical check-ups. In the Spanish study; however, a correlation was observed between higher serum glycated haemoglobin levels and other known risk factors for CVD - increased glycaemia, metabolic syndrome and obesity/overweight. A relation was observed between the occurrence of microalbuminuria and hypertension [25].

\section{WORK SCHEDULE}

Specific working conditions at sea such as long working hours and shift work are also associated with increased cardiovascular risk [7]. Unfortunately, we have failed to find studies describing the relationship between long working hours and CVD among seafarers; however, a meta-analysis of over 600,000 employees published by Lancet in 2015 confirmed the relationship between higher CVD risk (especially the risk of stroke) and long working hours [26]. There is also a relationship between long working hours and the risk of depression [27], which is a risk factor for CVD. Another large meta-analysis carried out by the Scandinavian team of Torquati et al. [28], covering over 17 thousand respondents, showed an adverse effect of shift work on cardiovascular risk, especially in case of people working in shifts for more than 5 years. Another aspect related to shift work is its correlation with higher occurrence of other known risk factors among people working in shifts such as obesity, smoking and eating more calories [29].

\section{PHYSICAL FACTORS}

Although the authors did not find any research on the population of seafarers that would document an increased cardiovascular risk caused by physical factors, numerous studies on other professional groups confirm the adverse 
impact of the above factors on the overall risk of CVD [27, 30]. During work seafarers are exposed to harmful physical factors [5, 31]. As shown by a Swedish study based on an online questionnaire and covering populations of almost 2000 Swedish seafarers [31], harmful factors most frequently reported by the respondents include noise $(83 \%$ of employees on the machine deck and over $70 \%$ of other employees) and vibrations (over $60 \%$ of employees machine deck). It is worth noting that in the case of noise, the adverse effect of exposure involves increasing the risk of obesity, diabetes, depression, sleep disorders and hypertension $[27,30]$; and in the case of vibrations increasing the risk of sleep disorders and depression [27].

\section{PSYCHOSOCIAL FACTORS}

At present, the ESC also emphasizes the adverse impact of psychosocial factors such as discrimination and a sense of lack of control at work on increasing CVD risk [7]. According to the aforementioned Swedish study, more than $20 \%$ of male seafarers and over $45 \%$ of female seafarers were exposed to harassment and depreciation at work [31].

\section{DISCUSSION}

The specificity of working at sea makes seafarers vulnerable to numerous harmful factors both during work and during leisure time. On the basis of available literature, we can see that the cardiovascular risk factors have been occurring for many years with varying frequency in the seaman population. Numerous researchers $[4,8,9]$ raise the still-persistent problem of overweight and obesity among seafarers as one of the most common risk factors (even in over $60 \%$ of respondents). Also, when analysing a group of seafarers with normal BMI values, one can observe a tendency to a higher normal BMI in people working at sea in comparison to the average BMI in the population of that nationality.

High prevalence of other classical risk factors such as smoking, type 2 diabetes or lipid disorders has also been confirmed in the seaman population $[4,9]$. However, the literature review carried out by Pougnet et al. [4] concerned the population of the respondents in the years 19902000, and the study published by Oldenburg et al. [8] was carried out in 2010, which is a relatively long time ago. Meanwhile, an Italian study [9] published in 2019 on a relatively large research group of seafarers did not confirm the higher incidence of hypertension and glycaemic disorders than in the general population. In this situation, one should consider whether this tendency also applies to other ethnic groups.

In assessing the prevalence of risk factors among the entire seafarer population, ethnic differences may pose a great difficulty - individual surveys are conducted on different ethnic groups; and there are discrepancies in the years in which individual studies were conducted. Discrepancies in the periods in which individual studies were performed date back even to the 10-year period, so we can say that we are dealing with a completely different research group. Changes in the population of seafarers result not only from the passage of time but also from changes in the legislation on the admission of seafarers after cardiovascular events or people with a diagnosed mental illness, increasing the percentage of chronically ill people in this occupational group. Moreover, as the authors of the German study [8] point out, longer working time at sea is associated with increased cardiovascular risk despite regular medical check-up.

Another underestimated group with an increased cardiovascular risk among seafarers are patients with rheumatism - there are no publications in the literature on the prevalence of rheumatic diseases within people working off-shore. We also cannot forget that exposure to the harmful effects of individual harmful factors depends on the position on the ship and is different for particular groups of seafarers.

\section{CONCLUSIONS}

Seafarers, regardless of nationality, have a higher cardiovascular risk than the general population. Although there are numerous publications on this subject, the issue of cardiovascular risk estimation in this group is still valid due to the changing population and a better understanding of current and the emergence of new cardiovascular risk factors.

\section{REFERENCES}

1. Statistics EH. Health statistics - Atlas on mortality in the European Union - data 1994-96. [Internet]. 2002. Available from:. http://epp.eurostat.ec.europa.eu/cache/ITY_OFFPUB/ATLAS/ EN/ATLAS-EN.HTM\%5CnC:\%5CEMH\%5CScannede artikler referanser\%5CRefMan2201.pdf.

2. Oldenburg M, Herzog J, Harth V. Seafarer deaths at sea: a German mortality study. Occup Med (Lond). 2016; 66(2): 135-137, doi: 10.1093/occmed/kqv153, indexed in Pubmed: 26409049.

3. Podolec J, Gajos G, Budziaszek $Ł$, et al. [Review of epidemiologic studies in cardiology in Poland]. Kardiol Pol. 2006; 64(9): 1031-1037, indexed in Pubmed: 17054040.

4. Pougnet R, Pougnet L, Loddé BL, et al. Cardiovascular risk factors in seamen and fishermen: review of literature. Int Marit Health. 2013; 64(3): 107-113.

5. Wójcik-Stasiak M. Assessment of the impact of genetic factors individual and work environment factors on medical case law, in an emergency cardiovascular events on the example of crew members of Polish ships offshore in 1988-2014; PhD thesis; Medical University of Gdańsk. (MUG): 2014.

6. Alves PM, Leigh R, Bartos G, et al. Cardiovascular events on board commercial maritime vessels: a two-year review. Int Marit Health. 2010; 62(3): 137-142, indexed in Pubmed: 21154300.

7. Piepoli MF, Hoes AW, Agewall S, et al. ESC Scientific Document Group. 2016 European Guidelines on cardiovascular disease prevention in clinical practice: The Sixth Joint Task Force of the European Society of Cardiology and Other Societies on Cardiovascular Disease Prevention in Clinical Practice (constituted by 
representatives of 10 societies and by invited experts)Developed with the special contribution of the European Association for Cardiovascular Prevention \& Rehabilitation (EACPR). Eur Heart J. 2016; 37(29): 2315-2381, doi: 10.1093/eurheartj/ehw106, indexed in Pubmed: 27222591.

8. Oldenburg M, Jensen $\mathrm{HJ}$, Latza $\mathrm{U}$, et al. The risk of coronary heart disease of seafarers on vessels sailing under a German flag. Int Marit Health. 2010; 62(3): 123-128, indexed in Pubmed: 21154298.

9. Nittari G, Tomassoni D, Di Canio M, et al. Overweight among seafarers working on board merchant ships. BMC Public Health. 2019; 19(1): 45, doi: 10.1186/s12889-018-6377-6, indexed in Pubmed: 30626365.

10. Gregorio ER, Kobayashi J, Medina JR, et al. Knowledge, attitudes, and related practices of Filipino seafarers regarding cardiovascular diseases. Int Marit Health. 2016; 67(4): 214-222, doi: 10.5603/ IMH.2016.0039, indexed in Pubmed: 28009390.

11. Assmann G, Schulte H, Cullen P. New and classical risk factors-the Münster heart study (PROCAM). Eur J Med Res. 1997; 2(6): 237-242.

12. Clays $E$, Lidegaard M, De Bacquer D, et al. The combined relationship of occupational and leisure-time physical activity with all-cause mortality among men, accounting for physical fitness. Am J Epidemiol. 2014; 179(5): 559-566, doi: 10.1093/aje/kwt294, indexed in Pubmed: 24305575.

13. Geving IH, Jørgensen KU, Thi MS, et al. Physical activity levels among offshore fleet seafarers. Int Marit Health. 2007; 58(1-4): 103-114, indexed in Pubmed: 18350980.

14. EMSA. Seafarers' Statistics in the EU Statistical review (2014 data STCW-IS). 2016 (August).

15. Amenta F, Carotenuto A, Molino I. Psychological stress in seafarers: a review. Int Marit Health. 2012; 63(4): 188-194.

16. Regulation of the Minister of Health and Social Welfare of 17 February 1993 on health conditions required from persons engaged in work on sea merchant ships, the mode of recognition of persons as capable or incapable of performing work, and the types.

17. Paczowski G. Regulation of the Minister of Health of 9 December 2015 on the health conditions required from seafarers to perform work on a seagoing vessels; Poland. 2011; 179.

18. Og K, Pracy O, Pracy B, et al. Maritime Labour Convention. 2006; 2006.

19. Keil U. Das weltweite WHO-MONICA-Projekt: Ergebnisse und Ausblick. Das Gesundheitswesen. 2005; 67(S 01): 38-45, doi: 10.1055/ s-2005-858240.

20. Aviña-Zubieta JA, Choi HK, Sadatsafavi M, et al. Risk of cardiovascular mortality in patients with rheumatoid arthritis: a meta-analysis of observational studies. Arthritis Rheum. 2008; 59(12): 1690-1697, doi: 10.1002/art.24092, indexed in Pubmed: 19035419.
21. Meek IL, Picavet HS, Vonkeman HE, et al. Increased cardiovascular risk factors in different rheumatic diseases compared with the general population. Rheumatology (Oxford). 2013; 52(1): 210-216, doi: 10.1093/rheumatology/kes194, indexed in Pubmed: 22847678.

22. Crowson CS, Liao KP, Davis JM, et al. Rheumatoid arthritis and cardiovascular disease. Am Heart J. 2013; 166(4): 622-628.e1, doi: 10.1016/j.ahj.2013.07.010, indexed in Pubmed: 24093840.

23. Iversen RTB. The mental health of seafarers. Int Marit Health. 2012; 63(2): 78-89, indexed in Pubmed: 22972547.

24. Beşikçi EB, Tavacıoğlu L, Arslan ö. The subjective measurement of seafarers' fatigue levels and mental symptoms. Maritime Policy \& Management. 2015; 43(3): 329-343, doi: 10.1080/03088839.2015.1047426.

25. Romero-Paredes MC, Reinoso-Barbero L, González-Gómez MF, et al. Improving cardiovascular health in Spanish seafarers. Int Marit Health. 2016; 67(1): 3-8, doi: 10.5603/IMH.2016.0002, indexed in Pubmed: 27029922.

26. Kivimäki M, Jokela M, Nyberg ST, et al. IPD-Work Consortium. Long working hours and risk of coronary heart disease and stroke: a systematic review and meta-analysis of published and unpublished data for 603,838 individuals. Lancet. 2015; 386(10005): 1739-1746, doi: 10.1016/S0140-6736(15)60295-1, indexed in Pubmed: 26298822.

27. Meneton P, Lemogne C, Herquelot E, et al. Primary Cardiovascular Disease Risk Factors Predicted by Poor Working Conditions in the GAZEL Cohort. Am J Epidemiol. 2017; 186(7): 815-823, doi: 10.1093/aje/kwx152, indexed in Pubmed: 28525584.

28. Torquati L, Mielke Gl, Brown WJ, et al. Shift work and the risk of cardiovascular disease. A systematic review and meta-analysis including dose-response relationship. Scand J Work Environ Health. 2018; 44(3): 229-238, doi: 10.5271/sjweh.3700, indexed in Pubmed: 29247501.

29. Ramin C, Devore EE, Wang W, et al. Night shift work at specific age ranges and chronic disease risk factors. Occup Environ Med. 2015; 72(2): 100-107, doi: 10.1136/oemed-2014-102292, indexed in Pubmed: 25261528.

30. Yang Ye, Zhang E, Zhang J, et al. Relationship between occupational noise exposure and the risk factors of cardiovascular disease in China. Medicine. 2018; 97(30): e11720, doi: 10.1097/ md. 0000000000011720.

31. Forsell $\mathrm{K}$, Eriksson $\mathrm{H}$, Järvholm $\mathrm{B}$, et al. Work environment and safety climate in the Swedish merchant fleet. Int Arch Occup Environ Health. 2017; 90(2): 161-168, doi: 10.1007/s00420-016-1180-0, indexed in Pubmed: 27815725. 